Published in final edited form as:

J Clin Oncol. 2008 June 10; 26(17): 2895-2900. doi:10.1200/JCO.2007.15.8428.

\title{
Multiple Myeloma Cancer Stem Cells
}

\author{
Carol Ann Huff and William Matsui \\ From the Sidney Kimmel Comprehensive Cancer Center and Department of Oncology, Johns \\ Hopkins University School of Medicine, Baltimore, MD
}

\begin{abstract}
Multiple myeloma is characterized by the clonal expansion of neoplastic plasma cells within the bone marrow, elevated serum immunoglobulin, and osteolytic bone disease. The disease is highly responsive to a wide variety of anticancer treatments including conventional cytotoxic chemotherapy, corticosteroids, radiation therapy, and a growing number of agents with novel mechanisms of action. However, few if any patients are cured with these modalities and relapse remains a critical issue. A better understanding of clonogenic multiple myleoma cells is essential to ultimately improving longterm outcomes, but the nature of the cells responsible for myeloma regrowth and disease relapse is unclear. We review evidence that functional heterogeneity exists in multiple myeloma and discuss potential strategies and clinical implications of the stem-cell model of cancer in this disease.
\end{abstract}

\section{INTRODUCTION}

\begin{abstract}
Neoplastic plasma cells are the hallmark of multiple myeloma. Like other chronic hematologic malignancies, the vast majority of myeloma plasma cells appear mature and quiescent. ${ }^{1}$ This suggests that functional heterogeneity may exist within myeloma and the potential for clonogenic growth is restricted to a minority population of cells. The normal counterpart of myeloma cells are terminally differentiated plasma cells that lack substantial replicative capacity. Instead, these cells arise from the maturation of B cells. Therefore, it is possible that aspects of the hierarchical nature of normal B-cell and plasma cell development is maintained in multiple myeloma, similar to the relationship observed between relatively immature hematopoietic and neural stem cells in myeloid leukemias and brain tumors, respectively. ${ }^{2-}$ ${ }^{5}$ Several studies have identified cells expressing the identical immunoglobulin idiotype and gene rearrangements as the neoplastic plasma cells within the blood and bone marrow of patients that phenotypically display a wide range of B-cell maturation. However, the role of these cells in the pathogenesis of the disease has been unclear and a point of controversy. We review the evidence for functional and phenotypic heterogeneity within the myeloma clone
\end{abstract}

Corresponding author: William Matsui, MD, Department of Oncology, Johns Hopkins University School of Medicine, CRB245, 1650 Orleans St, Baltimore, MD 21231; e-mail: matsuwi@jhmi.edu.

Authors' disclosures of potential conflicts of interest and author contributions are found at the end of this article.

AUTHOR CONTRIBUTIONS

Conception and design: Carol A. Huff, William Matsui

Manuscript writing: Carol A. Huff, William Matsui

AUTHORS' DISCLOSURES OF POTENTIAL CONFLICTS OF INTEREST

Although all authors completed the disclosure declaration, the following author(s) indicated a financial or other interest that is relevant to the subject matter under consideration in this article. Certain relationships marked with a " $U$ " are those for which no compensation was received; those relationships marked with a "C" were compensated. For a detailed description of the disclosure categories, or for more information about ASCO's conflict of interest policy, please refer to the Author Disclosure Declaration and the Disclosures of Potential Conflicts of Interest section in Information for Contributors.

Employment or Leadership Position: None Consultant or Advisory Role: None Stock Ownership: None Honoraria: None

Research Funding: William Matsui, Geron Corp Expert Testimony: None Other Remuneration: None 
and the existence of myeloma stem cells. In addition, we discuss similarities between cancer stem cells in multiple myeloma and normal adult stem cells and the potential that these shared stem-cell properties may provided the basis for novel antimyeloma therapies.

\section{FUNCTIONAL HETEROGENEITY IN MULTIPLE MYELOMA}

Examination of bone marrow samples from patients with multiple myeloma typically reveals an infiltration of mature plasma cells that resemble their normal counterparts. In addition to phenotypic similarities, myeloma plasma cells are functionally competent with the ability to produce monoclonal immunoglobulin. Because normal plasma cells are terminally differentiated and lack long-term proliferative potential, the nature of the replicating compartment that results in tumor growth has been a central question in myeloma. The growth fraction of myeloma plasma cells has been examined both in vitro and in vivo and these studies have found that the majority of plasma cells are quiescent, especially at diagnosis, suggesting that tumor growth is restricted to a specialized cell population. ${ }^{6-8}$ Early data suggesting that myeloma cells may be functionally heterogeneous arose from the studies of Bergsagel and Valeriote ${ }^{9}$ examining the growth properties of Adj PC-5 cells, a mouse plasma cell tumor generated by the injection of incomplete Freund's adjuvant and heat-killed staphylococci. The in vivo growth properties of Adj PC-5 cells were studied by examining the capacity of bone marrow-derived tumor cells to form tumor colonies within the spleens of recipient mice after intravenous injection, similar to the methods used to establish the existence and frequency of normal mouse hematopoietic stem cells. In contrast to more rapidly growing mouse leukemia or lymphoma models in which the ability to form splenic tumor colonies was a property held by a large proportion of tumor cells, in vivo colony formation of Adj PC-5 cells was restricted to a minority of cells and estimated to be at a frequency of 1 in 1,000 to 4,000. Moreover, cells from the splenic tumor colonies could be serially transplanted into secondary recipients demonstrating that injected cells were capable of self-renewal.

In vitro studies later confirmed the heterogeneous growth potential of Adj PC-5 cells following the development of a primary cell culture colony assay. ${ }^{10}$ Utilizing feeder layers consisting of mouse renal tubule cells and optimized cell culture conditions, the frequency of tumor colony formation was limited to a small number of cells, similar to the in vivo studies. Other distinct mouse myelomas were examined using this assay and similarly demonstrated that colony formation was limited to a minority of cells. Although these studies demonstrated that mouse myelomas display functional heterogeneity, the growth characteristics of primary human tumors could not be determined until the development of an in vitro culture system by Salmon and Hamburger. ${ }^{11,12}$ In their initial report, more than $86 \%$ of tumor samples from patients with multiple myeloma were capable of colony formation, and clonogenic growth occurred at a frequency of 1 in 100 to 100,000 cells. Dissociation of colonies and replating induced further colony formation suggesting these cells were capable of self-renewal similar to serial transplantation in the murine experiments. Rare clonogenic growth exhibited by both mouse and human myelomas could represent the restriction of proliferative capacity to a small, functionally unique, subset of cancer cells. Alternatively, clonogenic growth potential is equal among all cells, but only a few express this property at any point in time. However, sufficient investigational tools were not available at the time that could distinguish between these possibilities.

\section{PHENOTYPIC HETEROGENEITY IN MULTIPLE MYELOMA}

Unique immunoglobulin idiotype and gene sequences provide a highly specific means to establish clonal relationships in B-cell malignancies and have allowed the phenotypic variation of tumor cells to be studied within individual patients. The established relationship between normal B cells and plasma cells prompted investigations that myeloma plasma cells were 
derived from clonotypic B cells. Early evidence that peripheral blood lymphocytes were clonally related to myeloma plasma cells was provided by studies in which anti-idiotype antibodies formed against $\mathrm{M}$ protein were found to identify phenotypic B cells in the peripheral blood and bone marrow of patients with multiple myeloma. ${ }^{13-15}$ Subsequent studies utilized the ability to sequence tumor-specific immunoglobulin heavy chain gene sequences that could be used to examine the clonal relationship between plasma cells and B cells at the molecular level. Utilizing allele-specific oligonucleotide-based polymerase chain reactions, a number of studies have demonstrated that clonal cells expressing B-cell, rather than plasma cell, antigens could be found at varying frequencies within the bone marrow or peripheral blood of myeloma patients. ${ }^{16-22}$ In addition, chromosomal alterations found within myeloma plasma cells have been detected in CD19+ B cells by fluorescence in situ hybridization. ${ }^{23}$ Genetic, phenotypic, and functional studies have suggested that these clonotypic cells are equivalent to memory B cells. The analysis of immunoglobulin heavy chain gene sequences in myeloma demonstrates extensive somatic hypermutation without evidence of intraclonal variation suggesting that they arise from a postgerminal center compartment. ${ }^{24-26}$ Furthermore, clonotypic

immunoglobulin gene rearrangements have been found within cells displaying a pre-switched isotype and in cells expressing surface CD19, CD27, and lacking CD38 consistent with memory B cells. $16,27,28$

The clinical relevance of circulating clonotypic cells has been controversial, but studies have suggest that these cells are drug resistant and they appear to persist after systemic therapy. ${ }^{29-33}$ Functional evidence that these cells may give rise to myeloma plasma cells has been provided by evidence that earlier B cells can differentiate into immunoglobulin secretingplasma cells in vitro. ${ }^{34,35}$ The clonogenic growth potential of clonotypic B cells has also been studied both in vitro and in vivo. These cells have been found to engraft immunodeficient nonobese diabetic severe combined immunodeficiency mice and give rise to clonal plasma cells that recapitulate bone disease and monoclonal immunoglobulin production similar to the clinical disease. ${ }^{36-38}$ Furthermore, using an in vitro clonogenic assay, we found that colony formation was not a property of cells expressing the characteristic surface antigen CD138 that is expressed by myeloma and normal plasma cells. ${ }^{39}$ Instead, cells lacking CD138 but expressing B-cell surface antigens formed tumor colonies that could be serially replated. Similarly, CD138+ plasma cells were incapable of engrafting nonobese diabetic severe combined deficiency mice whereas CD138- cells, later defined to phenotypically resemble memory B cells, produced disease in immunodeficient mice. ${ }^{38,39}$ These results contrast with those examining the growth of primary myeloma specimens within severe combined immunodeficiency mice implanted with human or rabbit bone fragments. ${ }^{40-42}$ In these models, CD138+ plasma cells directly implanted into the ectopic bone can proliferate and be retransplanted into secondary recipients, whereas earlier B cells lack engraftment potential. The reasons for these discrepancies are unclear but they likely represent the intrinsic differences between the animal models used, similar to studies examining the growth of human leukemias. $2,3,43$ It is possible that the barriers of xenotransplantation also play a role in these discrepancies and the characterization of clonogenic cells from a number of unique mouse models of myeloma may clarify this issue. ${ }^{43 a-46}$

\section{STEM-CELL CHARACTERISTICS OF B CELLS}

The prospective identification of cancer stem cells in myeloid leukemias and brain tumors has been guided by the previously established surface phenotype of normal hematopoietic and neural stem cells, respectively. ${ }^{2-5}$ These data suggest some human cancers arise from the deregulation of stem cells or progenitors that normally have self-renewal potential. The ability of clonotypic B cells to recapitulate multiple myeloma in immunodeficient mice suggests that these cells represent the cancer stem cell in multiple myeloma. In contrast to normal stem cells in most adult tissues, B cells represent a committed compartment without multilineage 
potential. However, they have the capacity to undergo self-renewal at multiple steps during their development unlike hematopoiesis and neural development in which self-renewal is largely restricted to the most primitive cellular compartments. Self-renewal within the adaptive immune system is required during clonal selection to provide the highest degree of antigen specificity. Moreover, self-renewal maintains immune memory throughout life, and the longterm nature of adaptive immunity has been demonstrated in reports studying long-term B-cell memory after small pox vaccination which demonstrated antigen-specificity in patients vaccinated more than 50 years prior without additional antigen exposure. ${ }^{47,48}$ Another link between the adaptive immune system and normal stem cells has also been suggested in a recent study demonstrating that memory B and T cells express common gene signatures with normal long-term hematopoietic stem cells that are involved in the process of self-renewal. ${ }^{49} \mathrm{In}$ addition, asymmetric cell division is a hallmark of stem cells and self-renewal, and this process has been found to occur during the formation of effector and memory T cells. ${ }^{50}$ Therefore, the relationship between self-renewing cellular compartments cancer stem cells in multiple myeloma may be similar to those proposed in other tumors.

\section{STEM-CELL PROPERTIES OF CANCER STEM CELLS IN MULTIPLE MYELOMA}

The ability of multiple myeloma stem cells to self-renew and give rise to differentiated effectors (ie, plasma cells) are two properties they share with normal adult stem cells. Another property of normal stem cells is resistance to toxic injury, and the continual risk of relapse among patients treated with standard therapies suggest that myeloma stem cells should also be relatively drug resistant. Resistance to standard cytotoxic chemotherapeutics agents and ionizing radiation has been demonstrated for leukemic and brain tumors stem cells, respectively. ${ }^{51-53}$ In multiple myeloma, several novel agents have been recently approved for clinical use. Since these drugs have unique mechanisms of action, we recently examined the relative affects of these agents on cell subsets in multiple myeloma. ${ }^{38} \mathrm{We}$ found that multiple myeloma cancer stem cells were relatively resistant to both standard cytotoxic compounds and novel agents in vitro compared with the myeloma plasma cells. These results may explain the ability of these drugs to produce disease responses seen as decreased mature cell compartments and suggest that they lack the ability to impact long-term outcomes. Furthermore, it appears that myeloma stem cells display properties common to normal stem cells, such as expression of membrane-bound drug transporters, intracellular detoxification enzymes, and quiescence. Thus, the chemoresistance of cancer stem cells may be mediated by multiple processes similar to those that protect normal stem cells.

The similarities between normal adult stem cells and myeloma cancer stem cells suggest that specific signaling pathways conserved between these cell types can serve as therapeutic targets. For example, highly conserved signaling pathways are required for axial patterning during embryonic development, such as Notch, Wnt, and Hedgehog. Accumulating data have demonstrated that these pathways play a role in regulating normal stem cells and the pathogenesis of a wide variety of human cancers, including multiple myeloma. ${ }^{54-60}$ Recently, a role for these developmental pathways in regulating cancer stem cells has begun to emerge. Aberrant activation of Hedgehog signaling has been identified in multiple myeloma and may have distinct biologic effects on plasma cells or stem cells. ${ }^{59,60}$ Within plasma cells, this pathway primarily mediates survival similar to a number of other signal transduction pathways. In contrast, the Hedgehog signaling pathway appears to regulate the fate decisions of myeloma cancer stem cells. Pathway activation by ligand results in the expansion of immature myeloma cells, whereas the inhibition of signaling utilizing a ligand-neutralizing monoclonal antibody or antagonists of the positive mediator of pathway signaling, smoothened, induces plasma cell differentiation. 
Mammalian DNA polymerase is incapable of fully replicating the ends of linear DNA duplexes. In order to limit chromosomal shortening during successive rounds of DNA replication, telomeres are synthesized by telomerase at the terminal ends of DNA. ${ }^{61}$ Telomerase consists of a reverse transciptase subunit, TERT, and an RNA template component, TR or TERC, and enzyme activity is required for the maintenance of normal stem cells. A striking example of the requirement for telomerase activity in stem cells is dyskeratosis congenita in which functional mutation of TERT or TERC results in exhaustion of the hematopoietic stem cell pool and aplastic anemia. ${ }^{62,63}$ Telomerase activity is normally restricted to stem and progenitor cells and is downregulated during differentiation. In mature cells, the lack of telomerase activity results in telomere shortening to a critical threshold and cellular senescence. It has been well known that telomerase activity is a common feature of most cancers and in multiple myeloma correlates with clinical outcomes. ${ }^{64,65}$ The role of telomerase in cancer stem cells has been largely speculative, but recent examination of multiple myeloma has suggested that it is active within both immature stem cells and mature plasma cell compartments. ${ }^{66}$ Inhibition of telomerase activity using pharmacologic inhibitors ultimately results in the loss of myeloma stem-cell self-renewal in vitro, suggesting that this approach may be clinically active against malignant precursors.

Similar to other chronic hematologic malignancies incurable with standard cytotoxic agents, allogeneic stem-cell transplantation can be curative in a subset of patients with multiple myeloma. 67,68 The favorable long-term outcomes with allogeneic transplantation have been attributed to the graft-versus-tumor effect, suggesting that immunologic antitumor strategies may have the potential to inhibit multiple myeloma stem cells. The idiotype of the monoclonal immunoglobulin is an attractive antigenic target because of its high degree of tumor specificity and vaccination trials utilizing purified $M$ protein have been undertaken. A recent study examined the effects of idiotype vaccination on circulating clonotypic B cells and found a reduction of these cells in four of six patients. ${ }^{69}$ In contrast, there was little change in M protein levels during the evaluation period, suggesting that this approach may be preferentially active against tumor precursors. Another potential immune target that may be preferentially expressed within multiple myeloma stem cells is the embryonic stem-cell-associated antigen SOX2. SOX2 was initially identified by screening reactive antibodies present in patients with monoclonal gammopathy of unknown significance but absent in those with multiple myeloma. 70 Subsequent analysis demonstrated that the SOX2 expression was a feature of clonogenic myeloma cells and that stimulation of anti-SOX2 immunity could limit clonogenic tumor growth of primary samples in vitro. Tumor infiltrating lymphocytes have been long recognized to exhibit antitumor immunity, and the specificity of T cells derived from the bone marrow of patients with myleoma has been examined. ${ }^{71}$ These marrow infiltrating lymphocytes display significantly greater tumor specificity compared with peripheral blood lymphocytes after in vitro activation and expansion using anti-CD3/CD28 beads. Furthermore, activated marrow infiltrating lymphocytes were capable of inhibiting both mature plasma cells and clonogenic myeloma stem cells. Taken together, these results suggest that immune-based approaches hold promise as multiple myeloma stem-cell-targeting strategies.

\section{CHALLENGES FACING THE CLINICAL TRANSLATION OF MULTIPLE MYELOMA CANCER STEM CELLS}

A major challenge in translating the cancer stem-cell hypothesis will be evaluating the efficacy of novel therapeutic strategies generated from basic studies of clonogenic myeloma cells. Traditional measures of response have relied on the serial measurement of serum and urine $\mathrm{M}$ proteins and bone marrow plasmacytosis, and these criteria have evolved over time as investigators have sought to more stringently define complete remissions based on the belief that the total disappearance of detectable tumor burden correlates with overall survival benefit. In the initial WHO criteria, complete remissions were defined by resolution of the serum or 
urine $\mathrm{M}$ protein. A negative immuno-fixation test was subsequently added by the European Group for Blood and Marrow Transplantation to the criteria required to achieve a complete remission followed by normalization of the serum free light chain assay and absence of clonal plasma cells by immunohistochemistry in the recently proposed uniform response criteria. ${ }^{72}$,

73 However, neither the magnitude nor the kinetics of the response have been shown to impact overall survival, although the use of molecular techniques to define prognostic patient categories may identify subsets of patients in which this relationship holds true. ${ }^{74-76}$ These parameters are not likely to be helpful in assessing early changes in myeloma stem cells since they evaluate changes in the burden of malignant plasma cells. Therefore, the best indicators of response to multiple myeloma stem-cell-targeted approaches at present may be progressionfree and overall survival, but these end points have typically required large numbers of patients and prolonged periods of follow-up.

New trial designs that incorporate novel end points will be needed to study myeloma stemcell-targeted therapies. One potential strategy is to incorporate these approaches with existing therapies to determine whether they prevent tumor regrowth and prolong the duration of remissions after cytoreduction with chemotherapeutic or novel agents. This approach could be studied in a randomized phase II design comparing the primary end point of response duration between patients receiving induction therapy alone with those additionally administered a myeloma stem-cell-directed therapy. The demonstration of a significant difference in conjunction with evidence for the specificity of these approaches would lend support to the clinical importance of eradicating myeloma stem cells. Thus, a secondary end point could be correlative laboratory studies directly assessing multiple myeloma cancer stem cells that might include the use of serial clonogenic assays. Furthermore, the quantitative detection of circulating myeloma stem cells by flow cytometry utilizing combinations of surface antigen expression and functional stem-cell assays may be used to monitor cells during treatment. ${ }^{38}$ As our understanding of myeloma stem cells continues to evolve, additional insights into how best to optimize the timing and sequence of therapies will be likely to improve.

\section{CONCLUSION}

The functional heterogeneity of multiple myeloma has been well established, and evidence has emerged for the clonogenic potential of circulating clonotypic cells with properties similar to normal memory B cells. However, the exact phenotype of the clonogenic cell has not been definitively established and controversy remains. Similar discrepancies exist in other human cancer, such as colon and pancreatic adenocarcinomas. ${ }^{77-80}$ These differences may be attributable to variation among the assay systems used to measure clonogenic growth, especially using distinct in vivo mouse models, as well as inherent intrapatient variability when studying primary clinical specimens. It is likely that definitive proof of cancer stem cells in multiple myeloma or any other disease will likely be answered by actual improvement in longterm outcomes using clinical strategies based on cancer stem-cell biology rather than an exhaustive study of the various model systems. However, growing knowledge regarding the basic biology of multiple myeloma, such as the identification of prognostic categories based on cytogenetic alterations or transcriptional profiling may allow multiple myeloma to serve as a model system to address general questions regarding cancer stem-cell biology.

\section{Acknowledgements}

Supported by Grants No. CA107040, CA93657, CA1539632 from the National Institutes of Health, The International Myeloma Foundation, The Sidney Kimmel Foundation for Cancer Research, and by the American Society of Clinical Oncology.

We thank Sarah Brennan and Richard J. Jones for critically reviewing the manuscript. We apologize to authors of significant reports that have been omitted due to space limitations. 


\section{References}

1. Kyle RA, Rajkumar SV. Multiple myeloma. N Engl J Med 2004;351:1860-1873. [PubMed: 15509819]

2. Lapidot T, Sirard C, Vormoor J, et al. A cell initiating human acute myeloid leukaemia after transplantation into SCID mice. Nature 1994;367:645-648. [PubMed: 7509044]

3. Bonnet D, Dick JE. Human acute myeloid leukemia is organized as a hierarchy that originates from a primitive hematopoietic cell. Nat Med 1997;3:730-737. [PubMed: 9212098]

4. Singh SK, Hawkins C, Clarke ID, et al. Identification of human brain tumour initiating cells. Nature 2004;432:396-401. [PubMed: 15549107]

5. Hemmati HD, Nakano I, Lazareff JA, et al. Cancerous stem cells can arise from pediatric brain tumors. Proc Natl Acad Sci U S A 2003;100:15178-15183. [PubMed: 14645703]

6. Drewinko B, Alexanian R, Boyer H, et al. The growth fraction of human myeloma cells. Blood 1981;57:333-338. [PubMed: 7448427]

7. Hofmann V, Salmon SE, Durie BG. Drug resistance in multiple myeloma associated with high in vitro incorporation of 3H-thymidine. Blood 1981;58:471-476. [PubMed: 7259835]

8. Latreille J, Barlogie B, Johnston D, et al. Ploidy and proliferative characteristics in monoclonal gammopathies. Blood 1982;59:43-51. [PubMed: 6172171]

9. Bergsagel DE, Valeriote FA. Growth characteristics of a mouse plasma cell tumor. Cancer Res 1968;28:2187-2196. [PubMed: 5723963]

10. Park CH, Bergsagel DE, McCulloch EA. Mouse myeloma tumor stem cells: A primary cell culture assay. J Natl Cancer Inst 1971;46:411-422. [PubMed: 5115909]

11. Hamburger AW, Salmon SE. Primary bioassay of human tumor stem cells. Science 1977;197:461463. [PubMed: 560061]

12. Hamburger AW, Kim MB, Salmon SE. The nature of cells generating human myeloma colonies in vitro. J Cell Physiol 1979;98:371-376. [PubMed: 422663]

13. Mellstedt H, Hammarstrom S, Holm G. Monoclonal lymphocyte population in human plasma cell myeloma. Clin Exp Immunol 1974;17:371-384. [PubMed: 4219599]

14. Kubagawa H, Vogler LB, Capra JD, et al. Studies on the clonal origin of multiple myeloma: Use of individually specific (idiotype) antibodies to trace the oncogenic event to its earliest point of expression in B-cell differentiation. J Exp Med 1979;150:792-807. [PubMed: 92518]

15. King MA, Nelson DS. Tumor cell heterogeneity in multiple myeloma: Antigenic, morphologic, and functional studies of cells from blood and bone marrow. Blood 1989;73:1925-1935. [PubMed: 2785420]

16. Billadeau D, Ahmann G, Greipp P, et al. The bone marrow of multiple myeloma patients contains B cell populations at different stages of differentiation that are clonally related to the malignant plasma cell. J Exp Med 1993;178:1023-1031. [PubMed: 8350044]

17. Bakkus MH, Van RI, Van Camp B, et al. Evidence that the clonogenic cell in multiple myeloma originates from a pre-switched but somatically mutated B cell. Br J Haematol 1994;87:68-74. [PubMed: 7947257]

18. Bergsagel PL, Smith AM, Szczepek A, et al. In multiple myeloma, clonotypic B lymphocytes are detectable among CD19+ peripheral blood cells expressing CD38, CD56, and monotypic Ig light chain. Blood 1995;85:436-447. [PubMed: 7529064]

19. Chen BJ, Epstein J. Circulating clonal lymphocytes in myeloma constitute a minor subpopulation of B cells. Blood 1996;87:1972-1976. [PubMed: 8634446]

20. Szczepek AJ, Seeberger K, Wizniak J, et al. A high frequency of circulating B cells share clonotypic Ig heavy-chain VDJ rearrangements with autologous bone marrow plasma cells in multiple myeloma, as measured by single-cell and in situ reverse transcriptase-polymerase chain reaction. Blood 1998;92:2844-2855. [PubMed: 9763569]

21. Rasmussen T, Kastrup J, Knudsen LM, et al. High numbers of clonal CD19+ cells in the peripheral blood of a patient with multiple myeloma. Br J Haematol 1999;105:265-267. [PubMed: 10233390]

22. Pilarski LM, Giannakopoulos NV, Szczepek AJ, et al. In multiple myeloma, circulating hyperdiploid B cells have clonotypic immunoglobulin heavy chain rearrangements and may mediate spread of disease. Clin Cancer Res 2000;6:585-596. [PubMed: 10690543] 
23. Zojer N, Schuster-Kolbe J, Assmann I, et al. Chromosomal aberrations are shared by malignant plasma cells and a small fraction of circulating CD19+ cells in patients with myeloma and monoclonal gammopathy of undetermined significance. Br J Haematol 2002;117:852-859. [PubMed: 12060120]

24. Bakkus MH, Heirman C, Van Riet I, et al. Evidence that multiple myeloma Ig heavy chain VDJ genes contain somatic mutations but show no intra-clonal variation. Blood 1992;80:2326-2335. [PubMed: 1421403]

25. Sahota S, Hamblin T, Oscier DG, et al. Assessment of the role of clonogenic B lymphocytes in the pathogenesis of multiple myeloma. Leukemia 1994;8:1285-1289. [PubMed: 8057663]

26. Vescio RA, Cao J, Hong CH, et al. Myeloma Ig heavy chain V region sequences reveal prior antigenic selection and marked somatic mutation but no intraclonal diversity. J Immunol 1995;155:2487-2497. [PubMed: 7650379]

27. Rasmussen T, Jensen L, Johnsen HE. The clonal hierachy in multiple myeloma. Acta Oncol 2000;39:765-770. [PubMed: 11145430]

28. Rasmussen T, Lodahl M, Hancke S, et al. In multiple myeloma clonotypic. Leuk Lymphoma 2004;45:1413-1417. [PubMed: 15359642]

29. Pilarski LM, Belch AR. Circulating monoclonal B cells expressing P glycoprotein may be a reservoir of multidrug-resistant disease in multiple myeloma. Blood 1994;83:724-736. [PubMed: 7507731]

30. Pilarski LM, Szczepek AJ, Belch AR. Deficient drug transporter function of bone marrow-localized and leukemic plasma cells in multiple myeloma. Blood 1997;90:3751-3759. [PubMed: 9345062]

31. Kiel K, Cremer FW, Rottenburger C, et al. Analysis of circulating tumor cells in patients with multiple myeloma during the course of high-dose therapy with peripheral blood stem cell transplantation. Bone Marrow Transplant 1999;23:1019-1027. [PubMed: 10373068]

32. Rottenburger C, Kiel K, Bosing T, et al. Clonotypic CD20+ and CD19+ B cells in peripheral blood of patients with multiple myeloma post high-dose therapy and peripheral blood stem cell transplantation. Br J Haematol 1999;106:545-552. [PubMed: 10460621]

33. Rasmussen T, Jensen L, Honore L, et al. Frequency and kinetics of polyclonal and clonal B cells in the peripheral blood of patients being treated for multiple myeloma. Blood 2000;96:4357-4359. [PubMed: 11110713]

34. Caligaris-Cappio F, Bergui L, Gregoretti MG, et al. Role of bone marrow stromal cells in the growth of human multiple myeloma. Blood 1991;77:2688-2693. [PubMed: 1675130]

35. Caligaris-Cappio F, Bergui L, Tesio L, et al. Identification of malignant plasma cell precursors in the bone marrow of multiple myeloma. J Clin Invest 1985;76:1243-1251. [PubMed: 2931452]

36. Pilarski LM, Hipperson G, Seeberger K, et al. Myeloma progenitors in the blood of patients with aggressive or minimal disease: Engraftment and self-renewal of primary human myeloma in the bone marrow of NOD SCID mice. Blood 2000;95:1056-1065. [PubMed: 10648422]

37. Pilarski LM, Seeberger K, Coupland RW, et al. Leukemic B cells clonally identical to myeloma plasma cells are myelomagenic in NOD/SCID mice. Exp Hematol 2002;30:221-228. [PubMed: 11882359]

38. Matsui W, Wang Q, Barber J, et al. Clonogenic multiple myeloma progenitors, stem cell properties, and drug resistance. Cancer Res 2008;68:190-197. [PubMed: 18172311]

39. Matsui W, Huff CA, Wang Q, et al. Characterization of clonogenic multiple myeloma cells. Blood 2004;103:2332-2336. [PubMed: 14630803]

40. Yaccoby S, Barlogie B, Epstein J. Primary myeloma cells growing in SCID-hu mice: A model for studying the biology and treatment of myeloma and its manifestations. Blood 1998;92:2908-2913. [PubMed: 9763577]

41. Yaccoby S, Epstein J. The proliferative potential of myeloma plasma cells manifest in the SCID-hu host. Blood 1999;94:3576-3582. [PubMed: 10552969]

42. Yata K, Yaccoby S. The SCID-rab model: A novel in vivo system for primary human myeloma demonstrating growth of CD138-expressing malignant cells. Leukemia 2004;18:1891-1897. [PubMed: 15385929]

43. Namikawa R, Ueda R, Kyoizumi S. Growth of human myeloid leukemias in the human marrow environment of SCID-hu mice. Blood 1993;82:2526-2536. [PubMed: 8104540] 
43. Chesi AM, Robbiani DF, Sebag M, et al. AID-dependent activation of a MYC transgene induces multiple myeloma in a conditional mouse model of post-germinal center malignancies. Cancer Cell 2008;13:167-180. [PubMed: 18242516]

44. Radl J. Multiple myeloma and related disorders: Lessons from an animal model. Pathol Biol (Paris) 1999;47:109-114. [PubMed: 10192877]

45. Carrasco DR, Sukhdeo K, Protopopova M, et al. The differentiation and stress response factor XBP-1 drives multiple myeloma pathogenesis. Cancer Cell 2007;11:349-360. [PubMed: 17418411]

46. Boylan KLM, Gosse MA, Staggs SE, et al. A transgenic mouse model of plasma cell malignancy shows phenotypic, cytogenetic, and gene expression heterogeneity similar to human multiple myeloma. Cancer Res 2007;67:4069-4078. [PubMed: 17483317]

47. Crotty S, Felgner P, Davies H, et al. Cutting edge: Long-term B cell memory in humans after smallpox vaccination. J Immunol 2003;171:4969-4973. [PubMed: 14607890]

48. Hammarlund E, Lewis MW, Hansen SG, et al. Duration of antiviral immunity after smallpox vaccination. Nat Med 2003;9:1131-1137. [PubMed: 12925846]

49. Luckey CJ, Bhattacharya D, Goldrath AW, et al. Memory T and memory B cells share a transcriptional program of self-renewal with long-term hematopoietic stem cells. Proc Natl Acad Sci U S A 2006;103:3304-3309. [PubMed: 16492737]

50. Chang JT, Palanivel VR, Kinjyo I, et al. Asymmetric T lymphocyte division in the initiation of adaptive immune responses. Science 2007;315:1687-1691. [PubMed: 17332376]

51. Guzman ML, Neering SJ, Upchurch D, et al. Nuclear factor $\kappa$ B is constitutively activated in primitive human acute myelogenous leukemia cells. Blood 2001;98:2301-2307. [PubMed: 11588023]

52. Guzman ML, Rossi RM, Karnischky L, et al. The sesquiterpene lactone parthenolide induces apoptosis of human acute myelogenous leukemia stem and progenitor cells. Blood 2005;105:41634169. [PubMed: 15687234]

53. Bao S, Wu Q, McLendon RE, et al. Glioma stem cells promote radioresistance by preferential activation of the DNA damage response. Nature 2006;444:756-760. [PubMed: 17051156]

54. Taipale J, Beachy PA. The Hedgehog and Wnt signalling pathways in cancer. Nature 2001;411:349354. [PubMed: 11357142]

55. Houde C, Li Y, Song L, et al. Overexpression of the NOTCH ligand JAG2 in malignant plasma cells from multiple myeloma patients and cell lines. Blood 2004;104:3697-3704. [PubMed: 15292061]

56. Jundt F, Probsting KS, Anagnostopoulos I, et al. Jagged1-induced Notch signaling drives proliferation of multiple myeloma cells. Blood 2004;103:3511-3515. [PubMed: 14726396]

57. Derksen PWB, Tjin E, Meijer HP, et al. Illegitimate WNT signaling promotes proliferation of multiple myeloma cells. Proc Natl Acad Sci U S A 2004;101:6122-6127. [PubMed: 15067127]

58. Qiang YW, Walsh K, Yao L, et al. Wnts induce migration and invasion of myeloma plasma cells. Blood 2005;106:1786-1793. [PubMed: 15886323]

59. Peacock CD, Wang Q, Gesell GS, et al. Hedgehog signaling maintains a tumor stem cell compartment in multiple myeloma. Proc Natl Acad Sci U S A 2007;104:4048-4053. [PubMed: 17360475]

60. Dierks C, Grbic J, Zirlik K, et al. Essential role of stromally induced hedgehog signaling in B-cell malignancies. Nat Med 2007;13:944-951. [PubMed: 17632527]

61. Blasco MA. Telomeres and human disease: Ageing, cancer and beyond. Nat Rev Genet 2005;6:611622. [PubMed: 16136653]

62. Armanios M, Chen JL, Chang YPC, et al. Haploinsufficiency of telomerase reverse transcriptase leads to anticipation in autosomal dominant dyskeratosis congenita. Proc Natl Acad Sci U S A 2005;102:15960-15964. [PubMed: 16247010]

63. Yamaguchi H, Calado RT, Ly H, et al. Mutations in TERT, the gene for telomerase reverse transcriptase, in aplastic anemia. N Engl J Med 2005;352:1413-1424. [PubMed: 15814878]

64. Shay JW, Wright WE. Telomerase therapeutics for cancer: Challenges and new directions. Nat Rev Drug Discov 2006;5:577-584. [PubMed: 16773071]

65. Wu KD, Orme LM, Shaughnessy J Jr, et al. Telomerase and telomere length in multiple myeloma: Correlations with disease heterogeneity, cytogenetic status, and overall survival. Blood 2003;101:4982-4989. [PubMed: 12609839] 
66. Matsui W, Wang Q, Vala M, et al. Cancer stem cell targeting in multiple myeloma by GRN163L, a novel and potent telomerase inhibitor. Blood (ASH Annual Meeting) 2006;108:2540.(abstr 2540)

67. Gahrton G, Tura S, Ljungman P, et al. Allogeneic bone marrow transplantation in multiple myeloma: European Group for Bone Marrow Transplantation. N Engl J Med 1991;325:1267-1273. [PubMed: 1922221]

68. Bensinger WI. Allogeneic hematopoietic cell transplantation for multiple myeloma. Biomed Pharmacother 2002;56:133-138. [PubMed: 12046684]

69. Rasmussen T, Hansson L, Osterborg A, et al. Idiotype vaccination in multiple myeloma induced a reduction of circulating clonal tumor B cells. Blood 2003;101:4607-4610. [PubMed: 12576327]

70. Spisek R, Kukreja A, Chen LC, et al. Frequent and specific immunity to the embryonal stem cellassociated antigen SOX2 in patients with monoclonal gammopathy. J Exp Med 2007;204:831-840. [PubMed: 17389240]

71. Noonan K, Matsui W, Serafini P, et al. Activated marrow-infiltrating lymphocytes effectively target plasma cells and their clonogenic precursors. Cancer Res 2005;65:2026-2034. [PubMed: 15753403]

72. Blade J, Samson D, Reece D, et al. Criteria for evaluating disease response and progression in patients with multiple myeloma treated by high-dose therapy and haemopoietic stem cell transplantation: Myeloma Subcommittee of the EBMT. Br J Haematol 1998;102:1115-1123. [PubMed: 9753033]

73. Durie BGM, Harousseau JL, Miguel JS, et al. International uniform response criteria for multiple myeloma. Leukemia 2006;20:1467-1473. [PubMed: 16855634]

74. Durie BGM, Jacobson J, Barlogie B, et al. Magnitude of response with myeloma frontline therapy does not predict outcome: Importance of time to progression in Southwest Oncology Group chemotherapy trials. J Clin Oncol 2004;22:1857-1863. [PubMed: 15111617]

75. Blade J, Lopez-Guillermo A, Bosch F, et al. Impact of response to treatment on survival in multiple myeloma: Results in a series of 243 patients. Br J Haematol 1994;88:117-121. [PubMed: 7803233]

76. Haessler J, Shaughnessy JD Jr, Zhan F, et al. Benefit of complete response in multiple myeloma limited to high-risk subgroup identified by gene expression profiling. Clin Cancer Res 2007;13:70737079. [PubMed: 18056185]

77. O'Brien CA, Pollett A, Gallinger S, et al. A human colon cancer cell capable of initiating tumour growth in immunodeficient mice. Nature 2007;445:106-110. [PubMed: 17122772]

78. Dalerba P, Dylla SJ, Park Ik, et al. Phenotypic characterization of human colorectal cancer stem cells. Proc Natl Acad Sci U S A 2007;104:10158-10163. [PubMed: 17548814]

79. Li C, Heidt DG, Dalerba P, et al. Identification of pancreatic cancer stem cells. Cancer Res 2007;67:1030-1037. [PubMed: 17283135]

80. Hermann PC, Huber SL, Herrler T, et al. Distinct populations of cancer stem cells determine tumor growth and metastatic activity in human pancreatic cancer. Cell Stem Cell 2007;1:313-323. [PubMed: 18371365] 